\title{
Effective Blended Learning Techniques
}

\author{
Deborah Gill, Ph.D., Pennsylvania State University, DuBois, USA
}

\begin{abstract}
Blended learning is becoming more prevalent in higher education courses. Reasons for blending range from accommodating more students to improving the quality of courses offered. The purpose of this paper is twofold: (1) to discuss student attitudes towards blended courses versus face-to-face versus completely online courses, and (2) to consider the effects of different blended learning techniques on overall learning.
\end{abstract}

Keywords: Blended Learning, teaching, language teaching, tasked-based learning

\section{INTRODUCTION}

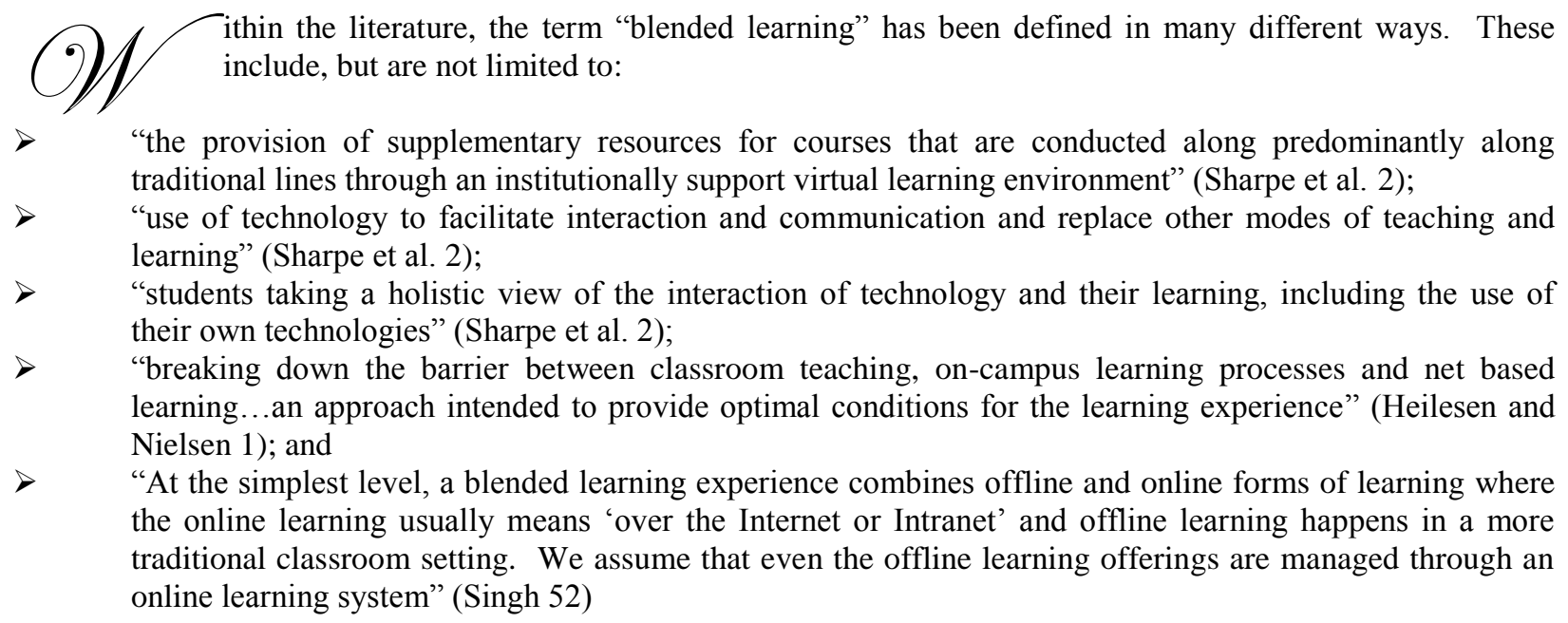

For purposes of this paper, we will define blended learning as the interweaving of face-to-face instruction with online technologies. Figure 1 illustrates this idea.

Figure 1 illustrates a blended learning course according to our definition. Briefly (we will discuss the components in more depth within the discussion section below), the course is broken into two parts ${ }^{1}$ : Face-to-Face instruction and Blended Technologies. During the face-to-face sessions, students have an opportunity to ask questions to clarify work which has been assigned within the blended technologies. Once all clarifications have been made (which generally are few), the face-to-face session takes on a new dynamic, that of project- or task-based learning.

Concurrently, blended technology tasks are solidly linked to the face-to-face component and provide the foundation to function in within the context of those sessions. The blended technologies component also consists of two branches: (1) static activities which include all information and work which can be done on an individual basis (i.e., downloading and/or reading materials, taking quizzes, etc.) and (2) active activities, which include activities which may be individual or in collaboration with other individuals in the course. These activities may be

\footnotetext{
${ }^{1}$ The percentage of time for each part varies depending upon institution and, in some instances, even among different courses at different institutions. For the present study, we will presume that the split is even, i.e., fifty percent face-to-face and fifty percent blended technologies.
} 
synchronous or asynchronous in nature. Some examples include: participating on a threaded discussion board, attending an online lecture, visiting a professor during virtual office hours, participating in a stock market simulation, etc. In other words, any activity in which an individual must take an active role.

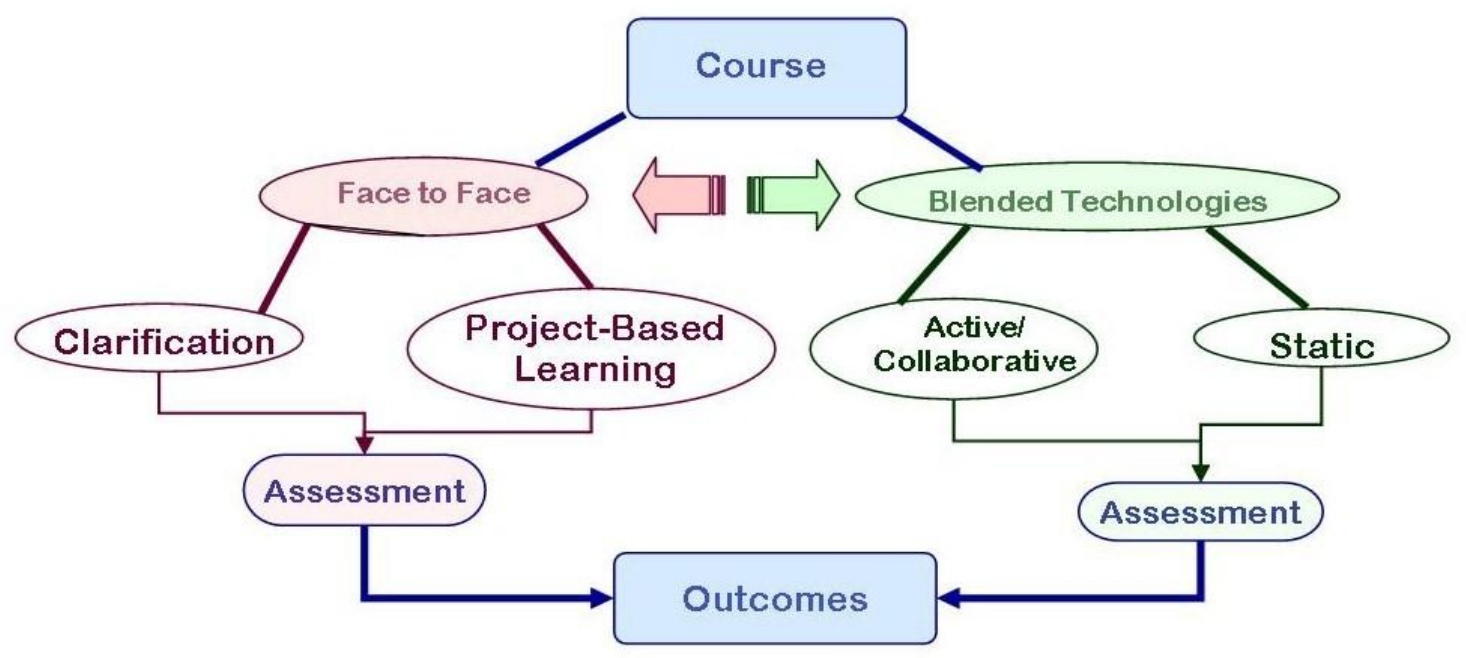

Figure 1: Blended Learning Course

As Figure 1 shows, as the course progresses, assessment instruments are used in both the face-to-face sessions as well as the blended technologies in order to gauge student attitude, motivation, and reaction to a blended learning course as well as track student learning throughout the course. Finally, with these assessment instruments, course outcomes can be gathered, evaluated, and compared with non-blended learning courses. The data may then be used to make improvements and changes in courses to meet the needs of the students as well as faculty and the institution.

Keeping Figure 1 in mind, the present study proposes to answer the following three research questions:

$>\quad$ Research Question \#1: Do student attitudes and motivation differ in blended learning courses compared to face-to-face courses?

$>\quad$ Research Question \#2: Are certain blended learning techniques more advantageous than others?

\section{METHODOLOGY}

\section{Design of the Study}

In order to answer our three Research questions, a case based pilot study was used. Student attitudes and motivation were studied as well as the effective blended learning techniques in a number of different disciplines, with the focus on language learning, the area of specialization of this author. Quantitative as well as qualitative data was gathered for language learning courses. Qualitative data was gathered from interviews which were used to analyze students' motivation, impact of class size, and effective blended learning techniques in multiple disciplines.

\section{Participants}

The study included a total of 253 university students enrolled in basic Spanish language courses at The Pennsylvania State University, courses which are generally either taken to fulfill a deficiency (Spanish 001) or taken to meet a language requirement for a Bachelor of Arts degree in some discipline. 


\section{Procedures of the Study}

The study was conducted over a two year period, spanning three-course basic Spanish language sequence. During the two year period, a blended learning model of instruction was used in all courses. In the first year, students attended face-to-face sessions four days a week, with one of these four days taking place in a computerenhanced classroom and online ${ }^{2}$. The three other days were spent on a combination of speaking, reading, listening, and writing activities to improve all four language skills. During the second year, students attended face-to-face sessions two days a week and were required to participate in blended learning activities the remaining two days. The two days in which students attended class were conducted using project- and task-based learning activities.

At the beginning of each semester, students were provided with orientation on how to participate in the blended learning activities. This orientation covered topics such as how to use the class management system to access their electronic workbook and lab manual, the class blog, the drop boxes for activities, and their instructor's virtual office. They were also introduced to the webcams, voice recorders, and virtual learning environments that they would be using for some collaborative activities.

Students were informed about the expectations with regard to the blended portion of their course, including the requirement that they must complete all activities on a weekly basis. The amount of time spent on blended learning activities would depend on an individual student's motivation to complete assignments.

\section{Data Collection}

Pre- and post-surveys were used to collect data in relation to student motivation, blended learning courses, and specific blended learning activities. Students were given a seven question language attitude questionnaire at the beginning and end of the semester in order to elicit feedback on attitude towards learning a language, blended learning activities, and language learning itself. In addition, students were given questionnaires in relation to both the face-to-face portion of the course as well as the different blended learning activities throughout the semester. Each questionnaire was given as a pre- and post-activity survey. The language attitude questionnaire as well as an example of the learning activity questionnaire can be found as Appendix A and B, respectively.

In addition to the data collected in language courses over the past two years, qualitative data with respect to blended learning techniques was also gathered from individual faculty members in other disciplines. A short, openended questionnaire was sent out to those teaching blended courses on this author's campus. This questionnaire can be found as Appendix C.

\section{DISCUSSION}

Qualitative and quantitative data analysis strategies were used in this study. As the purpose of this paper is to look at student motivation with regard to blended learning techniques, and because of space limitation, we will only discuss data related to the blended learning half of the full course.

Learning is fostered under certain circumstances, including the motivational context, interaction with both peers and teachers, and a high degree of learning activity. In order to have a perception of a student's motivation to learning a language, at the beginning and end of each semester, all students were given a pre- and post-language attitude questionnaire in order to observe attitude towards language learning, computer use, and basic skills in general. The results of this questionnaire can be found in Table 1 and 2 below:

\footnotetext{
${ }^{2}$ Students were allowed to connect outside of the classroom on the day of the online course if they chose. During the first year, students tended to choose connecting within their classroom; however, during the second year, students chose to connect outside of the classroom more frequently.
} 
Table 1: Pre-Language Attitude Questionnaire

\begin{tabular}{|c|c|c|}
\hline Survey questions & Mean (Group 1) & Mean (Group 2) \\
\hline I enjoy doing things on the computer. & 4.72 & 4.63 \\
\hline I enjoy lessons on the computer. & 3.21 & 3.09 \\
\hline I think it takes a long time to finish when I use the computer. & 3.12 & 3.00 \\
\hline Working with a computer makes me nervous. & 2.98 & 2.85 \\
\hline Computers do not scare me at all. & 3.42 & 3.50 \\
\hline I can learn more from computers than books. & 3.16 & 2.86 \\
\hline I believe that it is very important for me to learn to use a computer. & 4.23 & 4.40 \\
\hline I get a sinking feeling when I think of trying to use a computer. & 2.89 & 3.02 \\
\hline I enjoy speaking Spanish in class. & 3.18 & 3.28 \\
\hline I enjoy practicing my Spanish online with others. & 3.02 & 3.21 \\
\hline I enjoy writing. & 4.13 & 4.00 \\
\hline I enjoy writing in Spanish. & 3.62 & 3.54 \\
\hline I enjoy blogging in Spanish. & 2.63 & 2.61 \\
\hline I enjoy reading. & 4.32 & 4.18 \\
\hline I enjoy reading on the Internet. & 4.22 & 3.98 \\
\hline I enjoy reading in Spanish. & 3.65 & 3.58 \\
\hline I enjoy reading in Spanish on the Internet. & 3.23 & 3.16 \\
\hline
\end{tabular}

Table 2: Post-Language Attitude Questionnaire

\begin{tabular}{|c|c|c|}
\hline Survey question & Mean (Group 1) & Mean (Group 2) \\
\hline I enjoy doing things on the computer. & 4.67 & 4.78 \\
\hline I enjoy lessons on the computer. & 3.60 & 3.82 \\
\hline I think it takes a long time to finish when I use the computer. & 3.22 & 3.14 \\
\hline Working with a computer makes me nervous. & 2.43 & 2.38 \\
\hline Computers do not scare me at all. & 4.26 & 4.41 \\
\hline I can learn more from computers than books. & 3.34 & 3.10 \\
\hline I believe that it is very important for me to learn to use a computer. & 4.43 & 4.48 \\
\hline I enjoy speaking Spanish in class. & 3.45 & 4.23 \\
\hline I get a sinking feeling when I think of trying to use a computer. & 2.37 & 2.45 \\
\hline I enjoy writing. & 4.10 & 4.20 \\
\hline I enjoy writing in Spanish. & 3.43 & 4.16 \\
\hline I enjoy blogging in Spanish. & 2.23 & 3.21 \\
\hline I enjoy reading. & 4.41 & 4.20 \\
\hline I enjoy reading on the Internet. & 4.53 & 4.12 \\
\hline I enjoy reading in Spanish. & 3.38 & 3.96 \\
\hline I enjoy reading in Spanish on the Internet. & 3.47 & 4.19 \\
\hline
\end{tabular}

In both Tables 1 and 2, Group 1 refers to the group of students in a traditional classroom, while the Group 2 results refer to students in a blended learning course. The mean scores are based on a five point scale. Table 1 indicates minimal attitudinal differences with respect to computers, their use, and language learning (writing, speaking and reading). The results in the above tables are similar for the different skills; therefore, because of space constraints, we will discuss the general attitude questions as well as writing skill development here.

Comparing the post-language attitude results in Table 2 with the pre-language results in Table 1, within groups and between groups, it is possible to note some differences. First, looking at both groups, we see that students are more comfortable using computers, possibly due to the high use of technology in all courses. Second, with regard to the statement "I think it takes a long time to finish when I use the computer", we note little difference in Group 2, whereas in Group 1 this question has a higher mean. Further investigation of this question appears not be necessarily relate to writing, but rather to homework done on the computer. A representative written response in reply to this question is the following: "It's okay in helping me with my Spanish, but there always seems to be some sort of complications in doing the homework." 
In Group 1, the instructor follows the textbook from page to page, activity to activity. There are guided input and output writing activities, focusing on the grammatical and functional points in that particular section. In Group 2, the blended courses, students use multimedia and authentic realia for some of their writing activities, therefore providing a wider diversity of topics.

A second possible explanation is related to the free writing and blog activities and the responses given to the students. The non-technology-enhanced course (Group 1) turned in free writings at the end of the ten minute period and received credit. On the other hand, the blended learning course (Group 2) did their blogs online. Students received comments on their blogs and had the possibility to continue an individual interaction with the instructor.

Finally, motivation plays an important part in all aspects of language development. Biggs and Telfer (1987) suggest that learning is fostered under certain circumstances. These include the motivational context, interaction with both peers and teachers, a well-structured knowledge base, and a high degree of learning activity. In addition, it is well-known that, in order for a student to learn a language and to become culturally competent, the student must be motivated and have a purpose for wanting to learn a language and about different cultures. Gardner and Lambert (1959) distinguished between two types of motivation: integrative and instrumental. Integrative motivation deals with a learner's positive attitude toward the target language group and its culture, including meeting and interacting with other members of the community. On the other hand, instrumental motivation deals with learning a language for a purpose, such as getting a job, passing an exam, etc.

The free writings/blogs were administered in to separate manners. As mentioned earlier, the blended learning group wrote blogs once a week and, in turn, the students in the traditional classroom were asked to write for ten minutes at the end of class once a week. The blended learning course students received comments on their blogs from their professor (and sometimes from other students!). On the other hand, the students in the traditional classroom did not receive any type of feedback, including not receiving the free writing back at all. A check was placed on top of the writing and in the grade book and that was the end of that week's free writing.

Through receiving some type of acknowledgment, those students in the blended learning course possessed both integrative and instrumental motivation by receiving a comment back from their instructor, being able to communicate their ideas and thoughts, and at the same time, implicitly picking up language that would help them in the future. On the other hand, the students in the traditional classroom had the instrumental motivation of doing the free writing in order to get the "check mark" and therefore the credit for doing the assignment. However, there was no integrative motivation for doing the assignment. This can be seen in both the topic selection (more "book" topics and less free topics) as well as the decline in the enjoyment in writing in the foreign language.

Similar results are seen with regard to questions related to other language learning skills and therefore will not be discussed here.

In addition to observing student attitude and motivation, each blended learning activity was accompanied by a pre- and post- questionnaire in likert format as well as four open-ended questions. At the beginning of the semester, students were asked questions related to a number of different static activities (i.e., threaded discussion boards, quizzes, etc.). At the end of the semester, students were given the same questionnaire in order to observe student perception of that particular type of activity.

As Figure 1 on page 2 shows that the blended learning component of a course is divided into two components: static and active/collaborative. A pre- and post-questionnaire for each static and active/collaborative activity was given. The example below for the use of a virtual community is representative of the type of survey which was given for each activity and the results of that survey. 
1. I enjoy lessons on the computer.
strongly disagree
12
3
45
strongly agree

2. I have used virtual communities, chats, IRC, etc. in classes before and enjoyed it. $\begin{array}{lllllll}\text { strongly disagree } & 1 & 2 & 3 & 4 & 5 & \text { strongly agree }\end{array}$

3. Working and collaborating with others is interesting.

$\begin{array}{lllllll}\text { strongly disagree } & 1 & 2 & 3 & 4 & 5 & \text { strongly agree }\end{array}$

4. It would be/is beneficial to talk with other language learners and native speakers of Spanish.

$\begin{array}{lllllll}\text { strongly disagree } & 1 & 2 & 3 & 4 & 5 & \text { strongly agree }\end{array}$

5. I prefer using a textbook than talking in class.

$\begin{array}{lllllll}\text { strongly disagree } & 1 & 2 & 3 & 4 & 5 & \text { strongly agree }\end{array}$

6. I prefer using a textbook and working alone than collaborating with other people.

$\begin{array}{lllllll}\text { strongly disagree } & 1 & 2 & 3 & 4 & 5 & \text { strongly agree }\end{array}$

7. I think it is difficult to work with other collaboratively on line.

$\begin{array}{lllllll}\text { strongly disagree } & 1 & 2 & 3 & 4 & 5 & \text { strongly agree }\end{array}$

A summary of the results of these questions can be seen in Table 1 below:

Table 4: Comparison of Blended Learning Questionnaire for the use of Virtual Communities

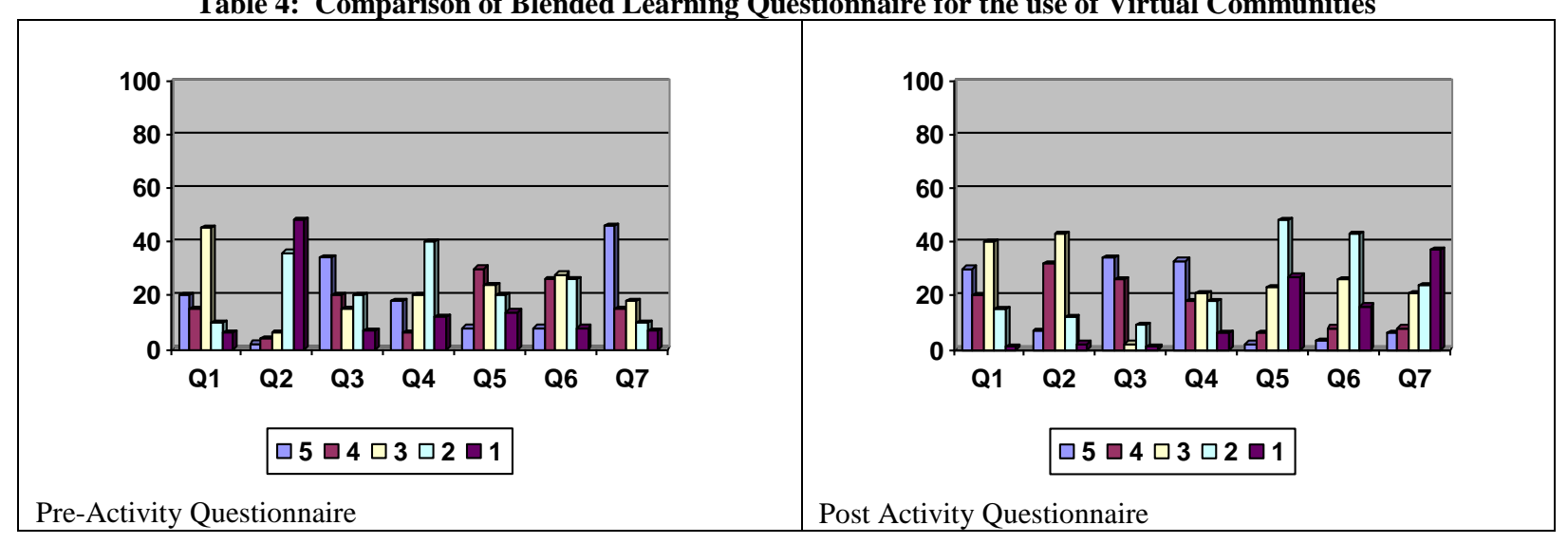

Two hundred fifty-three students responded to both the Pre- and Post-Language Attitude Questionnaires. The results support the idea that, when given the opportunity to build community, most students will choose collaborative activities over those in which they are working alone and passively learning.

It is well-known that, in order for a student to learn a language and to become culturally competent, the student must be motivated and have a purpose for wanting to learn a language and about different cultures. Gardner and Lambert (1959) distinguished between two types of motivation: integrative and instrumental. Integrative motivation deals with a learner's positive attitude toward the target language group and its culture, including meeting and interacting with other members of the community. On the other hand, instrumental motivation deals with learning a language for a purpose, such as getting a job, passing an exam, etc.

Looking at the Language Attitude Questionnaire results shown in Table 1 above, looking specifically at Questions 5 and 6, students noted that they preferred passive learning, i.e., using and reading their textbooks and working alone, to working collaboratively with others. However, after working within a virtual community 
environment, the results showed that students overwhelmingly preferred to collaborate with others than work alone. Their written comments also demonstrated this point:

- “All Spanish classes should be organized this way! In other classes I've taken, you just memorize and then forget because you aren't using it anymore. This way I have to remember so that I can keep using it!"

- $\quad$ "My partner was awesome! Even if I didn't know a word or how to say something, or if I wrote something that wasn't quite right, he didn't get mad, he just helped me. I've learned to some any cool expressions with him!"

- $\quad$ "This was really a challenge, but it was really fun too. I think I learned more Spanish this way even though I wasn't always just reading. And my tests were good too!"

- " "I learned a lot. I wish I could have done this in my other classes."

The majority of comments were similar to the ones above, although there were a few students who did not see the experience as positively:

- $\quad$ "I wish we worked more on grammar and had more practice with the verbs. I don't think working with other students helps at all."

- $\quad$ "Working with a native speaker was too stressful. If I wanted to talk with native speakers I would either go to another country to do it or I would go to a chat room. What a waste of time."

- "I was only taking this class because I had to. Why should I have to talk with people I don't know?"

The students who were positively affected by the virtual community activities possessed integrative motivation and viewed the experience very positively. The more they worked with their collaborative partners and the more they interacted in the environment, they became part of the community. Test results were not affected negatively with the more student-centered classroom interactions. To the contrary, test results have shown an increase in all five skills. On the other hand, students who were less responsive appear to possess more instrumental motivation for taking Spanish, i.e., passing the class because it was a requirement, wanting more book work, tending to mean more teacher-centered learning.

Figure 1 also points out that an overall assessment of the blended learning activities at the end of each course (i.e., each semester) is done. For each static and active activity, the pre- and post-activity questionnaires were analyzed and an average was determined. Table 5 below illustrates the results.

Table 5: Semester Blended Learning Activities

\begin{tabular}{|l|c|c|}
\hline \multicolumn{1}{|c|}{ Activity } & Pre-Semester Questionnaires & Post-Semester Questionnaires \\
\hline Threaded Discussion Boards & 2.10 & 2.84 \\
\hline Blogging (Written) & 2.37 & 2.73 \\
\hline Blogging (Video) & 1.98 & 3.71 \\
\hline Online Quizzes & 3.01 & 3.56 \\
\hline Individualized Games & 3.41 & 3.29 \\
\hline Online Workbook & 2.67 & 3.69 \\
\hline Virtual Learning Environment & 2.81 & 3.10 \\
\hline Video Conferencing & 2.06 & 3.01 \\
\hline Online Collaborations & 2.13 & 3.98 \\
\hline Podcasts & 3.54 & \\
\hline
\end{tabular}

Table 5 contains a list of all the blended learning activities in which students participate throughout a semester. Before students begin a particular blended learning activity, they are given a pre-activity questionnaire similar to the example given in Appendix B-2. After the final activity of that type during the semester, students are then given the same questionnaire. The results of these questionnaires are seen in Table 5 above. 
The numbers are on a scale of 1 (Strongly Disagree) to 5 (Strongly Agree). The above numbers are in response to question 2 on the pre- and post-semester questionnaire. The question for the Virtual Learning Environment was the following:

\section{Pre-semester questionnaire-Question 2}

2. I have used virtual communities, chats, IRC, etc. in classes before and enjoyed it. $\begin{array}{lllllll}\text { strongly disagree } & 1 & 2 & 3 & 4 & 5 & \text { strongly agree }\end{array}$

\section{Post-semester questionnaire-Question 2}

2. The use of the Virtual Community was enjoyable.

$\begin{array}{llllllll}\text { strongly disagree } & 1 & 2 & 3 & 4 & 5 & \text { strongly agree }\end{array}$

Analyzing Table 5, we see that there is an overall gain in all categories, although the gain is not large in a number of categories. These include written blogs, games, and podcasts. Through student comments, students found the written blogs less helpful than other activities:

$>\quad$ "Although the blog gave me a chance to practice my writing, I feel [sic] that it didn't really help me."

$>\quad$ "The blog was okay, but I never knew exactly what to write about, where I could at least have a topic with the threaded discussions."

"It was harder to do the blog than other things. I was always doing it at the last minute and I ended up repeating topics because I just didn't have the time to think about new things."

Many of the comments made by students included commentary regarding the threaded discussion. Students appeared to believe that the threaded discussion boards provided a better and more effective learning tool than the blogs.

The individual games had very little gain in enjoyment. Student response to both the pre- and postsemester showed general enjoyment and student written responses indicated that these individualized games were helpful for review before the face-to-face classes and/or for the online quizzes:

$>\quad$ "I love games! The puzzles, flash cards, and concentration games were really helpful when I was trying to learn the vocabulary. Since the lab is close to class, I could go and practice 10 minutes before class and have vocabulary ready to use. It was fun!"

"The games were okay with helping me with vocabulary. They broke up the monotony of the electronic workbook."

"The puzzles really made me have to think. I could recognize the vocabulary, but when I did the puzzles, I had to relate the word with others words and definitions. I think it helped me with my writing too because I learned different ways to say things. I wish there had been more of them!"

Finally, the podcasts did not have a significant gain (0.44). However, podcasts themselves were already popular with students and therefore the expectation was already there. In the language courses, there were activities which were related to each podcast that a student listened to. These podcasts were at levels which were slightly above the comprehension level of students (known as " $n+1$ "-Krashen 1989). Krashen's Monitor Hypothesis states that:

Our fluency in production is thus hypothesized to come from what we have 'picked up', what we have acquired, in natural communicative situations. Our 'formal knowledge' of a second language, the rules we learned in class and from texts, is not responsible for fluency, but only has the function of checking and making repairs on the output of the acquired system. (Krashen and Terrell 30) 
As students could download the podcasts and listen to them anytime they wanted to, the activities themselves were seen by students as having a positive impact on a number of different language learning skillslistening comprehension, speaking, and writing - being the top three skills mentioned by students:

> One of my favorite activities for this class was the podcasts. I would put them on my Ipod and listen to them a number of times. Then when I did the activity, I could understand it better. I even listened to some podcasts in Spanish that weren't assigned!"

"The podcasts definitely helped me with my speaking. I learned vocabulary that we didn't learn in class and I didn't have as hard a time understanding my professor so I could participate more in class."

The blended learning activities which made the largest gains included the Virtual Learning Environment, video conferencing, and online collaborations.

\section{CONCLUSIONS}

The present study attempted to look at two Research Questions:

$>\quad$ Research Question \#1: Do student attitudes and motivation differ in blended learning courses compared to face-to-face courses?

$>\quad$ Research Question \#2: Are certain blended learning techniques more advantageous than others?

With regard to Research Question \#1, results tend to support blended learning courses when the blended course components are innovative, interesting, and active. Static blended activities also played an important part in attitude and motivation as students believed that these activities helped in learning, although the active activities were seen as more valuable.

Finally, with regard to Research Question \#2, the present study appears to show that blended learning activities which are more active, i.e., virtual learning environments, collaborations, etc., tend to be important learning activities for language learners. Students also stated that other activities - such as games and threaded discussions-were interesting and helpful for preparation of exams, but that they believed that the more active activities helped them to improve their overall language skills more.

All of the activities which have been discussed here can be emulated in any other discipline with the same, or even more, success. In addition to these types of activities for language learners, the author of this study also sent out a questionnaire to other faculty members in other disciplines who use a blended learning format in their courses. Because of space limitations, the complete review and discussion of these findings is not possible. For our purposes here, we include in this section blended learning courses which are divided evenly between blended learning activities and face-to-face courses. The following is a summary of blended learning techniques which were implemented in courses over the past two years and perceptions of those faculty and/or their students:

\section{Business}

Business faculty at the author's institution has taught blended learning courses for a number of years now. According to faculty, the results of these blended learning courses have had mixed results with regard to student motivation:

"Each semester is different in my marketing courses. One semester students will tell me that the business simulation was the best part of the course and the next the students have hated it. At times there are outside influences which will make a world of difference in the outcomes."

"This is the first semester that I've taught this course as a blended learning course (Supply Chain Management). Student reaction to the blended learning activities has been extremely positive to this point. There have been thoughtful questions and very active learning."

"My business management courses have been using simulations for a number of years now. Students learn how to run companies, look at profit-to-loss, and how the pieces of a business fit together. Student response has been very positive. On my semester evaluations, students inevitably have stated that the 'hands-on' aspect of the course is what they like best about the course." 


\section{Communications}

Communications faculty across the University College campuses have been incorporating blended learning to some extent for some time now. Although these courses are not traditional blended courses (i.e., little to no faceto-face contact hours are reduced), the faculty have claimed great success in these techniques as found in Mino and Butler (1997) in which traditional lecture approaches to communications courses are compared to collaborative approaches; Mino (1999) where the author discusses the results (i.e., positive) of infusing beginning public speaking courses with technology; and Mino (2001) provides an explanation and discussion of a change in paradigm from teacher-centered ("Instructional") to learning ("student-centered").

\section{AUTHOR INFORMATION}

Dr. Deborah Gill is an Associate Professor of Spanish at the Pennsylvania State University, DuBois campus, where she teaches undergraduate Spanish language and culture courses, as well as Women's Studies and the Capstone course for the four-year Letters, Arts and Sciences degree. She received her Ph.D. in Hispanic Applied Linguistics from the University of Southern California. Her primary research interests include language variation, languages in contact, second language acquisition, and technology in teaching.

\section{REFERENCES}

1. Ames, C. 1992. Classrooms: goals, structures, and student motivation. Journal of Educational Psychology, 84:261-271.

2. $\quad$ Biggs, J.B. and Telfer, R. 1987. The Process of Learning. Sydney: Prentice-Hall.

3. Gardner, R.C. and Lambert, W.E. 1959. Motivational variables in second language acquisition. Canadian Journal of Psychology. 13:266-272.

4. Heilesen, Simon B. and Jorgen Lerche Nielsen. 2004. Blended Learning on Campus. Proceedings of The International Conference on Education and Information Systems. Orlando July 21-25, Vol. 1, Applications of Information and Communication Technologies in Education and Training. Freddy Malpica et al., ed., 198-203.

5. Keller, J.M. 1987. Development and use of the ARCS Model of instructional design. Journal of Instructional Development. 10/3:2-10.

6. Krashen, S. 1989. We acquire vocabulary and spelling by reading: Additional evidence for the input hypothesis. The Modern Language Journal, 73:440-464.

7. Krashen, S. and Terrell, T. 1983. The natural approach. Pergamon: New York.

8. Mino, Mary. 1999. Will the Dazzling Promise Blind Us?: Using Technology in the Beginning Public Speaking Course. Basic Communication Course Annual. 11:79-107.

9. Mino, Mary. 2001. Shifting from an Instructional to a Learning Paradigm: Some Options for Communication Educators. Qualitative Research Reports in Communication. 2/1:14-23.

10. Mino, Mary and Marilynn Butler. 1997. A Traditional Lecture Approach Versus a Collaborative Approach: A Comparison of Student Performance Outcomes. Communication Research Reports. 14/4:493-507.

11. Sharpe, Rhona, Greg Benfield, George Roberts, Richard Francis. 2006. The undergraduate experience of blended e-learning: a review of UK literature and practice. Executive Summary. The Higher Education Academy, 1-4.

12. Singh, Harvey. 2003. Building Effective Blended Learning Programs. Educational Technology, 43/6:5154. 
APPENDIX A

Language Attitude Questionnaire

I. Language and computer questions. Choose the response which best represents your answer to the statement.

\begin{tabular}{|l|l|l|l|l|l|}
\hline & $\begin{array}{c}\text { Strongly } \\
\text { Disagree }\end{array}$ & Disagree & Undecided & Agree & $\begin{array}{c}\text { Strongly } \\
\text { Agree }\end{array}$ \\
\hline I enjoy doing things on the computer & & & & & \\
\hline I enjoy lessons on the computer. & & & & & \\
\hline $\begin{array}{c}\text { I think it takes a long time to finish } \\
\text { when I use the computer. }\end{array}$ & & & & & \\
\hline $\begin{array}{c}\text { Working with a computer makes me } \\
\text { nervous. }\end{array}$ & & & & & \\
\hline $\begin{array}{c}\text { Computers do not scare me at all. } \\
\text { I can learn more from computers than } \\
\text { books. }\end{array}$ & & & & & \\
\hline $\begin{array}{c}\text { I believe that it is very important for me } \\
\text { to learn to use a computer. }\end{array}$ & & & & & \\
\hline $\begin{array}{c}\text { I get a sinking feeling when I think of } \\
\text { trying to use a computer. }\end{array}$ & & & & & \\
\hline $\begin{array}{c}\text { I enjoyed the other Spanish classes that } \\
\text { I have taken. }\end{array}$ & & & & & \\
\hline I enjoy speaking Spanish in class. & & & & & \\
\hline $\begin{array}{c}\text { I enjoy practicing my Spanish on line } \\
\text { with others. }\end{array}$ & & & & & \\
\hline I enjoy writing. & & & & & \\
\hline I enjoy writing in Spanish. & & & & \\
\hline I enjoy blogging in Spanish. & & & & \\
\hline I enjoy reading. & & & & \\
\hline I enjoy reading on the Internet. & & & & \\
\hline I enjoy reading in Spanish. & & & & \\
\hline $\begin{array}{c}\text { I enjoy reading in Spanish on the } \\
\text { Internet. }\end{array}$ & & & & \\
\hline
\end{tabular}

APPENDIX B-1

Example of Blended Learning Activity Questionnaire (for Virtual Learning Environment)

1. I enjoy lessons on the computer.

$\begin{array}{lllllll}\text { strongly disagree } & 1 & 2 & 3 & 4 & 5 & \text { strongly agree }\end{array}$

2. I have used virtual communities in classes before and enjoyed it.
strongly disagree
12
$\begin{array}{lll}3 & 4 & 5\end{array}$
strongly agree

3. Working and collaborating with others is interesting.

$\begin{array}{lllllll}\text { strongly disagree } & 1 & 2 & 3 & 4 & 5 & \text { strongly agree }\end{array}$

4. It would be/is beneficial to talk with other language learners and native speakers of Spanish.
strongly disagree
1
2
3
45
strongly agree

5. I prefer using a textbook than talking in class.

$\begin{array}{lllllll}\text { strongly disagree } & 1 & 2 & 3 & 4 & 5 & \text { strongly agree }\end{array}$ 
6. I prefer using a textbook and working alone than collaborating with other people.

$\begin{array}{lllllll}\text { strongly disagree } & 1 & 2 & 3 & 4 & 5 & \text { strongly agree }\end{array}$

7. I think it is difficult to work with other collaboratively on line.

$\begin{array}{lllllll}\text { strongly disagree } & 1 & 2 & 3 & 4 & 5 & \text { strongly agree }\end{array}$

II. Your opinion. Please be frank in your answer to the following questions. Your responses are important to us.

1. What aspect of this assignment interested you the most?

2. What aspect of this assignment interested you the least?

3. Has this assignment helped you with your Spanish?

4. Do you think you have improved your Spanish with this method?

5. Has your attitude toward the language improved?

\section{APPENDIX B-2}

Example of Blended Learning Activity Questionnaire (for Threaded Discussions)

1. I enjoy lessons on the computer.

$\begin{array}{llllllll}\text { strongly disagree } & 1 & 2 & 3 & 4 & 5 & \text { strongly agree }\end{array}$

2. I have used threaded discussion boards in classes before and enjoyed it.

$\begin{array}{lllllll}\text { strongly disagree } & 1 & 2 & 3 & 4 & 5 & \text { strongly agree }\end{array}$

3. Reading, answering, and responding to others' posts is interesting.
strongly disagree
1
23
$4 \quad 5$
strongly agree

4. It would be/is beneficial to collaborate in writing with other language learners and native speakers of Spanish.

$\begin{array}{lllllll}\text { strongly disagree } & 1 & 2 & 3 & 4 & 5 & \text { strongly agree }\end{array}$

5. I prefer practicing in class and writing on paper than participating in threaded discussions. $\begin{array}{lllllll}\text { strongly disagree } & 1 & 2 & 3 & 4 & 5 & \text { strongly agree }\end{array}$

6. I prefer using a textbook and writing alone than participating in a threaded discussion board.

$\begin{array}{lllllll}\text { strongly disagree } & 1 & 2 & 3 & 4 & 5 & \text { strongly agree }\end{array}$

7. I think it is difficult to write and participate on threaded discussion boards.

$\begin{array}{lllllll}\text { strongly disagree } & 1 & 2 & 3 & 4 & 5 & \text { strongly agree }\end{array}$

II. Your opinion. Please be frank in your answer to the following questions. Your responses are important to us.

1. What aspect of this assignment interested you the most?

2. What aspect of this assignment interested you the least?

3. Has this assignment helped you with your Spanish?

4. Do you think you have improved your Spanish with this method?

5. Has your attitude toward the language improved? 
APPENDIX B-3

Example of Face-to-Face Activity Questionnaire (Task-Based Learning Activity)

1. I enjoy working with others in class.

$\begin{array}{llllllll}\text { strongly disagree } & 1 & 2 & 3 & 4 & 5 & \text { strongly agree }\end{array}$

2. I have completed collaborative tasks in classes before and enjoyed it.

$\begin{array}{llllllll}\text { strongly disagree } & 1 & 2 & 3 & 4 & 5 & \text { strongly agree }\end{array}$

3. Working and collaborating with others is interesting.

$\begin{array}{llllllll}\text { strongly disagree } & 1 & 2 & 3 & 4 & 5 & \text { strongly agree }\end{array}$

4. It would be/is beneficial to talk with other language learners and native speakers of Spanish. $\begin{array}{lllllll}\text { strongly disagree } & 1 & 2 & 3 & 4 & 5 & \text { strongly agree }\end{array}$

5. I prefer using a textbook than talking in class.

$\begin{array}{lllllll}\text { strongly disagree } & 1 & 2 & 3 & 4 & 5 & \text { strongly agree }\end{array}$

6. I prefer using a textbook and working alone than collaborating with other people. $\begin{array}{lllllll}\text { strongly disagree } & 1 & 2 & 3 & 4 & 5 & \text { strongly agree }\end{array}$

7. I think it is difficult to work with other collaborativelys. $\begin{array}{lllllll}\text { strongly disagree } & 1 & 2 & 3 & 4 & 5 & \text { strongly agree }\end{array}$

II. Your opinion. Please be frank in your answer to the following questions. Your responses are important to us.

1. What aspect of this assignment interested you the most?

2. What aspect of this assignment interested you the least?

3. Has this assignment helped you with your Spanish?

4. Do you think you have improved your Spanish with this method?

5. Has your attitude toward the language improved?

\section{APPENDIX C \\ Other Discipline Faculty Questionnaire}

1. Do you teach using a blended technology format?___ Yes___ No

2. What is the division of your class between face-to-face and blended technologies (i.e., $50 \%$ face-to-face/ $50 \%$ blended, $60 \%$ face-to-face $/ 40 \%$ blended, etc.)?

3. In the face-to-face portion of your class, what is the mode of your class (i.e., faculty lecture, small group discussion, task-based learning groups, project-based learning, etc.)?

4. In the blended portion of your course, what static materials/activities do you use (i.e., course readings, quizzing, etc.)?

5. In the blended portion of your course, what active/collaborative activities (if any) do you use (i.e., synchronous discussions, chats, etc.)?

6. Is preparation of a blended learning course more or less time demanding? Briefly explain.

7. If you have taught the same course outside of a blended learning context, were the results different than in the blended course (i.e., student motivation, grades, etc.)? Briefly explain.

8. What have student reactions to the blended course shown? Please give specific examples. 


\section{NOTES}

